\title{
Awareness on Climate Change and Adaptation Capability Needs of the Residents of Zambales, Philippines
}

\author{
Esmen M. Cabal ${ }^{1 *}$, Abdon Javier ${ }^{2}$, Marie Fe D. de Guzman $^{3}$
}

${ }^{1}$ Graduate School, President Ramon Magsaysay State University, Iba, Zambales, Philippines
${ }^{2}$ Jesus F. Magsaysay High School, Iba, Zambales, Philippines
${ }^{3}$ Graduate School, President Ramon Magsaysay State University, Iba, Zambales, Philippines

Article History

Received: 23.02.2021

Accepted: 07.03.2021

Published: 12.03 .202

Journal homepage: https://www.easpublisher.com

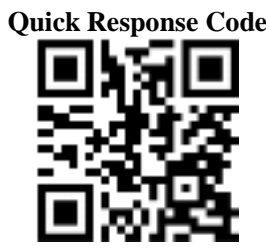

Abstract: The study aims to determine the awareness on the manifestations of climate change and the adaptation capability needs of the residents of Zambales to lessen the impact of climate change. The study was conducted in the different municipalities of Iba, Botolan and Palauig in the province of Zambales, Philippines. A total of 300 residents were included as respondents of the study. The respondents are vulnerable to the effects of climate change and extreme weather events in the province. The importance of the climate change awareness as the foundation of any climate change mitigation and adaptation capability building is included in this study. The findings show that the respondents are moderately aware in the manifestations of climate change. Considering Zambales, as the exit of tropical typhoons, the home of Mt. Pinatubo volcano, the La Nina and El Nino phenomenon playground, and the most sought victim of flooding brought about by mining activities within the province, the level of awareness of the residents as reflected in this study is very unusual. The manifestations of the climate change are very common in the province, however, the awareness of the residents is still low. The study believes that this issue must be addressed effectively to prepare the at-risk and vulnerable residents from the impact of climate change. Adaptation serves as the shield of the households from climate change. The adaptation practices include local and indigenous practices of the residents to survive the impact of the climate change. Particularly, the respondents moderately needed the shortterm, medium and long-term, integrated adaptation and basic capability enhancement, and information consolidation. The climate change awareness of the respondents differs according to their profile. The adaptation capability needs of the respondents do not differ accordingly.

Keywords: Climate Change, Awareness, Adaptation, Capability, Zambales.

Copyright (C) 2021 The Author(s): This is an open-access article distributed under the terms of the Creative Commons Attribution 4.0 International License (CC BY-NC 4.0) which permits unrestricted use, distribution, and reproduction in any medium for non-commercial use provided the original author and source are credited.

\section{INTRODUCTION}

Climate change and global warming have become issues of international concern in the recent decades. The United Nations Framework Convention on Climate Change [1] defined climate change as a change which is attributed directly or indirectly to human activities that alter the composition of the global atmosphere and which are in addition to natural climate variability observed over comparable time periods. It is one of the most serious problems that threatens the environment and humanity. Similarly, Holdren [2] defined climate change as any measurable trend in global climate towards extreme, which is in addition to rising global temperatures. It is a long-term measurable change in the elements of climate tending towards the extreme.
Global attention on climate change was sort for the first time by the Brundtland Report which revealed that the unsustainable development practices of humankind had caused the world's climate to a warming trend [3]. On the other hand, the public concern about climate change was not triggered by the Brundtland's report, but by the unusual northern hemisphere heat wave and drought of summer 1988 [4]. Consequently, the IPCC was established in 1989 to carry out periodic assessments on the global climate system and later the UN Framework Convention on Climate Change was adopted in 1992 to provide a framework for global action against climate change.

In the Philippines, the government has created the Philippine Council for Sustainable Development (PCSD) in response to its 1992 Earth Summit commitments. The Inter-Agency Committee on Climate Change (IACCC) was established a year earlier in 1991. 
More recently, the Presidential Task Force on Climate Change Adaptation and Mitigation (PTFCC) and the Advisory Council on Climate Change (ACCC) were also formed after the ratification of the Kyoto Protocol in 2003. Moreover, President Arroyo has made "Green Philippines", which is also a chapter in the Updated 2004-2010 Medium Term Philippine Development Plan, as one of her major priorities. Increasingly the Philippines, both at the national and local levels, has begun to pay attention to the adaptation of climate change, by promoting climate change risk management initiatives.

Climate change's impact on the Philippines is most often associated with extreme weather disturbances such as typhoons and floods, which, in turn, affect many other sectors of economic life. With 50.3 percent of its total area and 81.3 percent of the population vulnerable to natural disasters, the Philippines is considered a natural disaster hot-spot. About 85.2 percent of its US\$86 billion annual GDP is endangered as it is located in areas of risk [5]. Since 2000, approximately 3 million people have been affected by various disasters annually. Domestically, climate change is mostly felt through temperature, precipitation and sea level variations, which, in turn, impacts agriculture through crop yields, irrigation demands; changes in forest productivity, forest composition; water resources through variability of water supply and quality; coastal areas by erosion of beaches, inundation of coastal areas; species and natural areas through shifts in ecological zones, loss of habitat and species; as well as health impacts through infectious diseases, air quality-respiratory illnesses and water-related mortality.

The Department of Education shares its responsibility to educate the Filipinos on climate change and global warming. The department issued pertinent orders and guidelines to better facilitate and induced the important of environmental concerns among our students. The initiatives of the department includes the integration of Gulayan Sa Paaralan, Solid Waste Managment, and Tree Planting under the National Greening Program in 2004; the Massive, Intensive, and Sustain Tree-Planting, Tree-Growing, and Tree- Caring Program in 2008; and the Strengthening Environmental Education in Public and Private Schools as well as the Youth for Environment in Schools in 2011 are among the few projects of the department which focus on bringing up responsible and environment-friendly schools and students.

In lieu of this, the researcher felt the need to conduct a research that will serve as the baseline of the localization of the department initiatives on climate change and global warming in the province. The researcher believes that the conduct of this baseline study will improve the adoption of climate change awareness, mitigation and adaptation program of the division of Zambales. Furthermore, the conduct of the study will serve the province, and the Zambalenos to understand climate change better and help them live with the extreme changes safely.

Through the result of the study, appropriate actions may be determined to address the problems that may address the prevalence and occurrence of climate change and keep the stakeholders engaged in the mitigation of climate change. The Teachers would develop strategies to help students become resilient in the effects of climate change. The Pupils would develop a concern for the care of the environment and take serious ways on how to keep themselves safe and less vulnerable as to the effect of climate change. The Parents would be supportive in the care of the environment for everyone's safety in the community. The Local Government Units can derive programs, activities, and projects, institutionalized policies that may enhance protection of the community in the effect of climate change and mitigation of climate change as well as the development of the appropriate adaptation strategies.

\section{ObJectives OF THE STUdy}

This study aimed to determine the awareness on the manifestations of climate change and adaptation capability needs of the residents of Zambales, Philippines. Specifically, the study determined the profile of the resident-respondents; identified the residents' sources of information on climate change; identified the residents' awareness with regards to the manifestations of climate change be described; determined the climate change adaptation capability in terms of Short-term adaptation, Medium term and long term, integrated adaptation, Information consolidation and Awareness Raising; and tested the difference in the residents' awareness on the manifestations of climate change when grouped according to their profile and in the residents' climate change adaptation capability needs.

\section{Materials ANd MethodS}

The descriptive research design was used in this study. Descriptive method is the best because the nature of the research is documentary analysis, where facts, figures and data were already existing information.

This study was conducted in 2018 in the different Municipalities of Zambales, Philippines. These municipalities include Iba, Botolan and Palauig who in one way or another have already experienced the effects of climate change. The 300 respondents (selected using convenience-purposive sampling) of this study came from different group of residents who were and may be vulnerable to the effects of climate change 
and extreme weather events. The questionnairechecklist was the main instrument in gathering of data. The instrument was divided into four (4) parts. The first part gathers the profile of the residents. The second part gathers the sources of information on climate change of the residents. The third part gathers the residents' awareness on manifestations of climate change with 22 items and respondents were asked to rate from 5 (Very Much Aware) to 1 (Very Much Unaware). The last part gathers adaptation capability needs of the residents categorized into short-term adaptation, medium-and long-term adaptation, integrated adaptation, information consolidation and awareness raising with 35 total items and respondents were asked to rate from 5 (Highly Needed) to 1 (Not Needed). The final draft of the instrument was presented to the adviser for corrections and revisions. After the revisions, the instrument was then again submitted to the adviser for approval. The approved draft was validated among the residents of Minicipality of Masicloc, Zambales. Revisions from validation process were included. Upon the approval of the instrument, a permission to distribute the instrument has been granted by the Graduate School of RMTU, Zambales, Philippines. The same letter of request was also submitted to Mayors of the 3 municipalities of Zambales. Once the approval was handed, the researchers conducted the survey to the target residents. The survey was conducted personally. The confidentiality of their responses were treated very confidential.

Weighted mean was used to interpret the degree of responses in each of the indicators of the survey questionnaire. Analysis of Variance (ANOVA) was used as inferential statistics.

\section{RESULTS AND DisCUSSIONS}

\section{Profile of the Respondents}

Table-1: Summary of Results on the Profile of the Respondents

\begin{tabular}{|c|c|c|c|}
\hline \multirow{2}{*}{ Profile } & \multicolumn{3}{|c|}{ Faculty-Respondents $(\mathrm{N}=300)$} \\
\hline & Results & Frequency & Percentage \\
\hline \multirow[t]{3}{*}{ Sex } & Male & 94 & 31.33 \\
\hline & Female & 206 & 68.67 \\
\hline & Total & 300 & 100.00 \\
\hline Age & \multicolumn{3}{|c|}{ Mean Age $=44.95$ Years Old } \\
\hline \multirow[t]{7}{*}{ Place of Residence } & Near the River & 23 & 7.67 \\
\hline & Along the seashore & 43 & 14.33 \\
\hline & Near the mountain & 35 & 11.67 \\
\hline & Along fault line & 13 & 4.33 \\
\hline & In the lowland & 167 & 55.67 \\
\hline & Others & 19 & 6.33 \\
\hline & Total & 300 & 100.00 \\
\hline \multirow{7}{*}{ Educational Attainment } & Doctoral & 18 & 6.00 \\
\hline & Masters & 37 & 12.33 \\
\hline & Baccalaureate & 63 & 21.00 \\
\hline & High School & 112 & 37.33 \\
\hline & Elementary & 56 & 18.67 \\
\hline & None & 14 & 4.67 \\
\hline & Total & 300 & 100.00 \\
\hline \multirow[t]{13}{*}{ Occupation } & Office Employee & 32 & 10.67 \\
\hline & Public Utility Driver & 17 & 5.67 \\
\hline & Teacher & 15 & 5.00 \\
\hline & Barangay Official & 24 & 8.00 \\
\hline & Construction & 11 & 3.67 \\
\hline & Electrician/Electronic & 6 & 2.00 \\
\hline & Fisherman & 11 & 3.67 \\
\hline & Farmer & 11 & 3.67 \\
\hline & OFW & 8 & 2.67 \\
\hline & Vendor & 28 & 9.33 \\
\hline & Politician & 14 & 4.67 \\
\hline & Housekeeper & 123 & 41.00 \\
\hline & Tota1 & 300 & 100.00 \\
\hline Monthly Income & \multicolumn{3}{|c|}{ Mean Income $=\mathbf{5 6 2 3 2 . 8 2}$} \\
\hline
\end{tabular}


Table-1 shows the frequency and percentage distribution of the respondents in terms as to sex, age, place of residence, educational attainment, occupation and family monthly income. As for the result on sex variable, two hundred six (206) or 68.67 percent of the respondents are females, while ninety-four (94) or 31.33 percent are males. Most of the data collected were from female respondents as they represent more aggregately in the households, while others are from the sectors where most of the employed are female. The computed mean age of the respondents is 44.95 years old. The respondents belong to the stage of adulthood.

For the result on the place of residence, more than half of the population of the respondents (167 and 55.567 percent) lives in the lowland; followed by fortythree (43) or 14.33 percent lives along the seashore; thirty-five (35) or 11.67 percent lives near the mountain; twenty-three (23) or 7.67 lives near the river; and nineteen (19) or 6.33 percent lives in resettlement areas; and thirteen (13) or 4.33 percent lives along fault line. Majority of the residents lives on the low-lying areas/barangays which makes them prone to floods, flashfloods, and landslides. The vulnerability of the households is due to the province topography which is generally irregular with coastal plane and valleys. Moreover, the Zambales mountain range on the Eastern part occupies $60 \%$ of the total land area of the province; thus water from the mountains and from the shore meet on the low-lying barangay which is usually entrenched between the two areas.

In terms of educational attainment, the result reveals that most of the respondents (112 or 37.33 percent) are high school graduates; fifty-six (56) or 18.67 percent are elementary graduate; sixty-three (63) or 21 percent are baccalaureate degree graduate; and thirty-seven (37) or 12.33 percent are master's degree holder. The findings only confirm the Zambales. The
National Statistics Office (2013) reported that majority of the Zambaleños had only finished their secondary education and a very few pursued college and post baccalaureate degree studies. It is observed that girls commonly finished up to secondary education.

For the result on respondents' occupation, one hundred twenty three (123) or 41 percent are simple housekeepers; followed by thirty-two (32) or 10.67 percent clerk/office personnel/staff; twenty eight (28) or 9.33 percent are vendors; twenty-four (24) or 8 percent are barangay officials/workers; seventeen (17) or 5.67 percent are drives; and fifteen (15) or 5 percent are teachers. Most of the respondents of the present study are homemakers/housekeeper as source of data only shows that the study is community-based. The vast number of housekeepers came during the conduct of survey of which the housekeepers are the ones who are available during the conduct of the survey.

The mean family monthly income of the respondents is 56,232.22. The combined family income of the respondents reflects the major source of income of Zambalenos. National Statistics Office 2013 reported that fishing, farming, palay planting, and crop planting are the major sources of income of the households because of the nature of the land of Zambales which are a combination of agricultural and coastal areas. Filipino Families in the Poorest Decile Earn Six Thousand Pesos Monthly, on Average in 2012 (Results from the 2012 Family Income and Expenditure Survey) Reference Number: 2013-186 Release Date: Thursday, October 24, 2013. Philippine statistics Authority.

\section{Respondents' Source of Information about Climate Change}

Table-2 shows the frequency and rank of the respondents' source of information about climate change.

Table-2: Frequency and Rank Distribution of the Respondents Source of Information about Climate Change

\begin{tabular}{|l|l|l|}
\hline Source of Information About Climate Change & Frequency & Rank \\
\hline Television & 264 & 1 \\
\hline Radio & 256 & 2 \\
\hline Newspaper & 203 & 3 \\
\hline Internet & 78 & 8 \\
\hline Specialist Publications/Academe Journal & 67 & 5 \\
\hline Environmental Group (e.g. Worlwide) & 38 & 10 \\
\hline School/College/University & 85 & 7 \\
\hline Government Agencies/Information & 98 & 6 \\
\hline Public Libraries & 45 & 9 \\
\hline Friends/Family & 113 & 4 \\
\hline Local Council & 101 & 5 \\
\hline Energy Suppliers & 34 & 11 \\
\hline Other & 28 & 12 \\
\hline
\end{tabular}

Television, radio and newspaper are the top three or leading source of information about climate change as perceive by the respondents. On the other hand, environmental groups, energy supplier and other 
agencies which includes NGOs and related groups are perceived to be the least source of information about climate change.

A number of governments in developing countries are engaged in awareness-raising among their populations. Taking action to minimize the damaging effects of climate change is the responsibility of all stakeholders that include the governments, scientists, media organizations, development partners, and indeed the general public. Given the power of modern-day media, it is essential that media outlets are encouraged and empowered to tell personal stories about the effects of climate change [6]. The role of media in educating the public about climate change will ensure that those who are most vulnerable to its impacts - notably the rural poor - fully understand the effects on their lives and their futures, which will in turn help to sow the seeds of grass-roots action.

The effort of national government through mass media indeed is very powerful in the information dissemination of climate change. Furthermore, the initiate of the government can be seen through the continuous commitment and upgrading of combined Department of Science and technology (DOST) and Philippine Atmospheric, Geophysical and Astronomical Services Administration (PAGAS) facilities and systems.

\section{Respondents' Awareness on Manifestation of Climate Changes}

Table-3 shows the weighted mean, qualitative rating, and rank of the respondent's awareness on manifestation of climate changes.

\section{Table-3: Weighted Mean, Qualitative Rating, and Rank of the Respondents' Awareness on Manifestation of Climate Changes}

\begin{tabular}{|c|l|l|l|}
\hline Awareness on Manifestation of Climate Changes & Weighted Mean & Qualitative Rating & Rank \\
\hline 1. Increase in temperature an decrease in rainfall & 3.22 & Moderately Aware & 11 \\
\hline 2. Increase pollution and contaminant ratio & 2.97 & Moderately Aware & 16 \\
\hline 3. Coastal erosion & 3.11 & Moderately Aware & 13 \\
\hline 4. Frequency of natural hazards & 3.58 & Aware & 7 \\
\hline 5. Water shortage and contamination & 3.31 & Moderately Aware & 9 \\
\hline 6. Acidification of ocean & 2.84 & Moderately Aware & 15 \\
\hline 7. Coral bleaching & 3.05 & Moderately Aware & 11 \\
\hline 8. Flooding & 3.95 & Aware & 2 \\
\hline 9. Bushfire caused by heat and dryness & 3.66 & Aware & 5 \\
\hline 10. Storm surge & 3.34 & Moderately Aware & 5 \\
\hline 11. Tropical storm & 3.93 & Aware & 3 \\
\hline 12. Hotter climate & 3.93 & Aware \\
\hline 13. Cooler climate & 3.32 & Moderately Aware & 3 \\
\hline 14. Climate related landslide & 2.96 & Moderately Aware & 6 \\
\hline 15. Cyclonic region have cloudy skies & 2.85 & Moderately Aware & 6 \\
\hline 16. Anticyclonic regions have clear skies, more solar radiation, & 2.73 & Moderately Aware & 8 \\
\hline less rain increase heavy rains and soil moisture & & & \\
\hline 17. Rising food prices & 2.83 & Moderately Aware & 6 \\
\hline 18. Decrease of flora and fauna & 3.15 & Moderately Aware & 4 \\
\hline 19. Many plant species leafs out and flower significantly earlier & 3.05 & Moderately Aware & 4 \\
\hline 20. Annual plant responded more and more variably than & 2.81 & Moderately Aware & 4 \\
\hline perennials & & 3.77 & \\
\hline 21. Increase of disease Low income for farmers & 4.05 & Aware & 2 \\
\hline Average Weighted Mean & $\mathbf{3 . 2 9}$ & Moderately Aware \\
\hline
\end{tabular}

In descending order, the respondents are aware that climate change manifests low income for farmers (4.05); flooding (3.95); tropical storm and hotter climate (3.95); increase of disease (3.77); bushfire caused by heat and dryness (3.66); and frequency of natural hazards (3.58). The respondents are moderately aware that climate change manifests storm surge (3.34); cooler climate (3.32); water shortage and contamination (3.31); increase in temperature and decrease in rainfall (3.22); decrease of flora and fauna (3.15); coastal erosion (3.11); coral bleaching and many pant species leafs out and the flower significantly earlier (3.05). Similarly, the respondents are moderate aware that climate change manifests increase pollution and contamination ratio (2.97); climate related landslide (2.96); cyclonic region have cloudy skies (2.85); acidification of ocean (2.84); rising of food prices (2.83); annual plant respond more and more variably than perennials (2.81); and anticyclonic regions have 
clear skies, more solar radiation, less rain, increase heavy rains, and soil moisture (2.73).

The average weighted mean of the respondents on the manifestation of climate changes is 3.29 interpreted as moderately aware. The findings are in accordance with the study conducted by the World Development Report [7] which shows that flood and increase rainfall are predominantly the type of climate change manifestation of the province. Similarly, the study shows that the experience of the province towards the frequency of natural disasters is a result of climate change and global warning.

The frequency of the disaster experienced is also reflected in the Provincial Disaster Risk Reduction Management Program of the province. According to the report, one third of an average of 20 typhoons per year were crossing over Central Luzon, passing westward and exiting in Zambales, making high risk/prone areas vulnerable to hazards. This implies that an average of 7 out of 20 either hit or pass Zambales annually. Furthermore, Diviva et al., [8] reported that the coastal areas in Botolan become narrower each year; thus those living in the coatal areas are displaced. Meanwhile the coastal areas in San Narciso becomes broader each year, therefore illegal settlers pull in and settle along the coastal areas. The authorities believe that this is still an aftermath of the Mt. Pinatubo eruption in 1991 which may also have triggered by the extreme climate change in the province. Finally, according to Diviva et al., [8] an effective awareness includes preparedness and information, warning, and alert dissemination program which enhance and equip the vulnerable population how to behave and react to any hazards such as natural disasters and climate change effects. The households, as the smallest unit of the community must importantly and properly guided with the awareness and information of the hazards [9]. The search and rescue practice, pre-positioning of rescue materials, and preawareness programme on appropriate behavior, during and immediately after a hazard is a must.

\section{Respondents' Climate Change Adaptation Needs}

Table-4 shows the weighted mean, qualitative rating, and rank of the respondents' climate change adaptation needs. The adaptation needs are classified as short-term, medium and long-term, integrated adaptation and basic capacity enhancement, information consolidation, and awareness rising.

Table-4: Weighted Mean, Qualitative Rating, and Rank of the Respondents' Climate Change Adaptation Needs

\begin{tabular}{|l|l|l|l|}
\hline Climate Change Adaptation Needs & Average Weighted Mean & Qualitative Rating & Rank \\
\hline Short-term Adaptation & 3.19 & Moderately Needed & 4 \\
\hline Medium and Long-Term Adaptation & 3.36 & Moderately Needed & 1 \\
\hline Integrated Adaptation and Basic Capacity Enhancement & 3.32 & Moderately Needed & 2 \\
\hline Information Consolidation & 3.12 & Moderately Needed & 5 \\
\hline Awareness Raising & 3.24 & Moderately Needed & 3 \\
\hline
\end{tabular}

The average weighted mean of the climate change adaptation needs of the respondents in terms of the Short-Term Adaptation is 3.19 with a qualitative rating of moderately needed and ranked $1^{\text {st }}$. The short term adaptation need by majority of the respondents focused on the upgrade of drainage system; the need of natural retention of flood water; and the introduction of heat-resistant crop varieties and promotion. Found in the study of Intergovernmental Panel on Climate Change (IPCC) [10] it was revealed that the short term plan to climate change adaptation were identified on dealing with sea level rise and with rising damage in confined areas and from intense rainfall events; and crisis management arrangements and improvements in early warnings systems; the installation electrical generation equipment for water purification plants; and appropriate cultivation methods to address the declining crop quality and yields

The average weighted mean of the climate change adaptation needs of the respondents in terms of Integrated Adaptation and Basic Capability Enhancement is 3.32 with a qualitative rating of moderately needed and ranked $2^{\text {nd }}$. The finding imply that the respondents of the present study needed a review and collection of basic data and information relating to impact assessments and adaptation measures to further their capability to adapt on climate change. The integrated adaptation and basic capability enhancement should focus on heightened existing coastal protection; promotion of sustainable agricultural practice; and disaster response enhancement. In the study of Banwell Montoya, Opeñaet [11], the respondents prioritized the establishment of organizations that cooperate with local research institutions, non-profit organizations, and various types of organization for more efficient implementation of measures.

The average weighted mean of the climate change adaptation needs of the respondents in terms of Awareness Raising is 3.24 with a qualitative rating of moderately needed and ranked $3^{\text {rd }}$. To adapt to the climate change by means of awareness raising, respondents moderately needed the conduct of community workshop to review climate change risks and to improve civil preparedness for protecting health in case of extreme weather events. For Ayandele \& Jegede [12] the sharing of information among relevant government departments for the establishment of 
supportive institutional arrangements is very vital in developing awareness on the effects of climate change.

The average weighted mean of the climate change adaptation needs of the respondents' in Terms of Medium and Long Term Adaptation is 3.36 with a qualitative rating of moderately needed and ranked $4^{\text {th }}$. In terms of development of medium and long term adaptation for climate change, the respondents preferred to have a systematic water supply development to cope with recent frequent droughts; and the strengthening of measure to prevent outbreaks of infectious disease. In the study of Agboola \& Emmanuel [13] increase of protected forest area and improve forest fire warning; the land use regulations and incentives in affected areas; the construction (nesting) of ecosystem networks are what the respondents approved to be included in any plan for climate charge adaptation.

The average weighted mean of the climate change adaptation needs of the respondents in terms of Information Consolidation is 3.12 with a qualitative rating of moderately needed and ranked $5^{\text {th }}$. To be able to adapt to the climate change primarily on the aspect Information Consolidation, the respondents preferred the preparation of the geographic information system based community; the conduct of mapping risk and vulnerability; and the international support on technology transfer. According to Holten \& Van [14] the promotion of information exchange and collaborative research with local research instruments; and the setting up of internet portal sites for impacts and adaptation information that will be useful for the government.

According to World Bank [15], while the Philippines is not a major greenhouse gas (GHG) emitter, the country's GHG emission will continue to increase in the years to come. This growth will be due to a growing economy, heightened urbanization, increased demand and use of energy and the expected increase in the number of vehicles, all of which are highly dependent on crude oil for energy. The study recommends several measures among three main lines. One, strengthening planning, execution, and financing framework for climate change; two, enhancing leadership and accountability through monitoring, evaluation, and review of climate change policies and activities; and three, building capacity and managing change. These measures will make Filipinos adaptive to climate change.

Table-5: F-Test of Significant Difference of the Respondents' Awareness on Climate Change when grouped according to Profile

\begin{tabular}{|c|c|c|c|c|c|c|c|}
\hline Profile & Source of Variation & SS & df & MS & $\mathbf{F}$ & Fcrit & $\begin{array}{l}\text { Interpretation/ } \\
\text { Decision }\end{array}$ \\
\hline \multirow[t]{3}{*}{ Sex } & Between Groups & 25.61 & 1 & 25.61 & \multirow[t]{3}{*}{34.11} & \multirow[t]{3}{*}{3.87} & \multirow[t]{3}{*}{ Significant Reject Ho } \\
\hline & Within Groups & 223.76 & 298 & 0.75 & & & \\
\hline & Total & 249.37 & 299 & & & & \\
\hline \multirow[t]{3}{*}{ Age } & Between Groups & 49.81 & 10 & 4.98 & \multirow[t]{3}{*}{5.34} & \multirow[t]{3}{*}{1.86} & \multirow[t]{3}{*}{ Significant Reject Ho } \\
\hline & Within Groups & 269.82 & 289 & 0.93 & & & \\
\hline & Total & 319.64 & 299 & & & & \\
\hline \multirow[t]{3}{*}{ Place of Residence } & Between Groups & 22.86 & 5 & 4.57 & \multirow[t]{3}{*}{10.67} & \multirow[t]{3}{*}{2.24} & \multirow[t]{3}{*}{ Significant Reject Ho } \\
\hline & Within Groups & 126.05 & 294 & 0.43 & & & \\
\hline & Total & 148.92 & 299 & & & & \\
\hline \multirow[t]{3}{*}{ Education Attainment } & Bet Groups & 242.45 & 5 & 48.49 & \multirow[t]{3}{*}{101.5} & \multirow[t]{3}{*}{2.24} & \multirow[t]{3}{*}{ Significant Reject Ho } \\
\hline & Within Groups & 143.31 & 294 & 0.48 & & & \\
\hline & Total & 385.75 & 299 & & & & \\
\hline \multirow[t]{3}{*}{ Occupation } & Between Groups & 152.93 & 11 & 13.90 & \multirow[t]{3}{*}{29.44} & \multirow[t]{3}{*}{1.82} & \multirow[t]{3}{*}{ Significant Reject Ho } \\
\hline & Within Groups & 135.99 & 288 & 0.47 & & & \\
\hline & Total & 288.92 & 299 & & & & \\
\hline \multirow[t]{3}{*}{ Monthly Income } & Between Groups & 144.81 & 17 & 8.52 & \multirow[t]{3}{*}{15.80} & \multirow[t]{3}{*}{1.66} & \multirow[t]{3}{*}{ Significant Reject Ho } \\
\hline & Within Groups & 152.07 & 282 & 0.54 & & & \\
\hline & Total & 296.88 & 299 & & & & \\
\hline
\end{tabular}

Table-5 shows the test of significant difference of the respondents' awareness on climate change when grouped according to profile variable. Since the F computed value of the $\mathrm{F}$ test when the respondents are grouped according to sex (34.11), age (5.34), place of residence (10.67), educational attainment (101.51), occupation (29.44), and family monthly income (15.80) greater that the F critical value which is 3.87. 1.86. $2.24,2.24,1.82$ and 1.66 respectively, reject the null hypothesis of no significant differences. The perceived level of climate change awareness of the respondents differs according to their profile.

ANOVA Test of significant difference on the climate change adaptation capability needs

Table-6 shows the F-test of significant difference of the respondents' adaptation capability needs. Since the F-computed value of the respondents' 
adaptation capability needs which is 0.223607 is insignificantly comparable to F-critical vale which is 2.689628, accept null hypothesis of no significant difference. The adaptation capability needs of the respondents in terms of short-term, medium and long term, integrated adaptation, information consolidation, and awareness raising do not differ accordingly.

Table-6: ANOVA Test of Significant Difference on the Climate Change Adaptation Capability Needs of the residents of the selected towns of Zambales

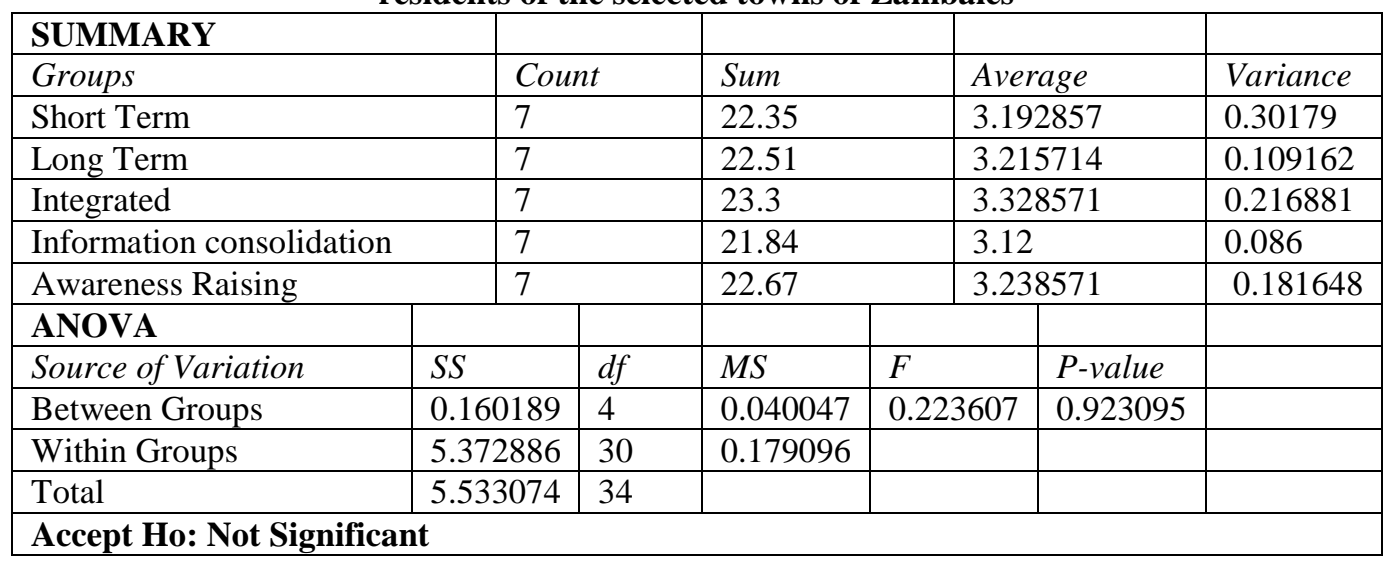

It is observed that in cases of effects of climate change like typhoon and flooding, everybody experiences the aftermath of the disaster, everybody needs help and services from the government. With this condition, The Philippine Development Plan 2011-2016 as the national development roadmap of the country aims for an economic growth of seven to eight per cent per year for at least six years, and achieving or surpassing the Millennium Development Goals. The PDP has identified disaster risk reduction and management (DRRM) and climate change adaptation (CCA) as major cross-cutting concerns. National policy promotes mainstreaming the integrated concerns of DRR and CCA into national and local decision making and planning processes as reflected in the legal framework for climate change adaptation in Republic Act No. 9729 of 2010 (Climate Change Act) and disaster risk reduction in Republic Act No. 10121 (Disaster Risk Reduction and Management Act of 2011). Both laws require local government units to adopt plans: the Local Climate Change Action Plan (LCCAP) and Local Disaster Risk Reduction and Management Plan (LDRRMP), respectively.

\section{CONCLUSIONS AND \\ RECOMMENDATIONS}

A typical resident vulnerable to climate change is a 45-year-old housekeeper who lives in the lowland, a high school graduate with a family monthly income of $56,233.00$ The residents' source of information about climate change is commonly the media which includes the television, radio, and newspaper.

The importance of the climate change awareness as the foundation of any climate change mitigation and adaptation capability building is included in this study. The awareness of the vulnerable and at-risk citizens on climate change was identified and believe to geared the study to an effective and resilient climate change program. Thus, the identification of the level of awareness among the residents was conducted. In general, the respondents are moderately aware in the manifestations of climate change. Considering Zambales, as the exit of tropical typhoons, the home of Mt. Pinatubo, the La Nina and El Nino phenomenon playground, and the most sought victim of flooding brought about by mining activities within the province, the level of awareness of the residents as reflected in this study is very unusual. The manifestations of the climate change are very common in the province, however, the awareness of the residents is still low. The study believes that this issue must be addressed effectively to prepare the at-risk and vulnerable residents from the impact of climate change.

Adaptation serves as the shield of the households from climate change. The adaptation practices include local and indigenous practices of the residents to survive the impact of the climate change. Particularly, the respondents moderately needed the short-term, medium and long-term, integrated adaptation and basic capability enhancement, and information consolidation.

The climate change awareness of the respondents differs according to their profile. The adaptation capability needs of the respondents in terms of short-term, medium and long term, integrated adaptation, information consolidation, and awareness raising do not differ accordingly.

In the light of the foregoing findings and conclusions of the study, it is recommended to begin the awareness program among the households and utilize the students to integrate and encourage their parent to 
engage in the climate change discussion and information dissemination; sustain the awareness and education campaign program of climate change by conducting regular activities among the residents, especially those at-risk and vulnerable residents; localized the climate change adaptive measures to suit the needs of the vulnerable population; continue to utilize the Department of Education in educating the youth, our future, to become environment -friendly, responsible, and concern citizens of the mother nature; lastly, thorough study should be conducted on how to strengthen the climate change education campaign and information dissemination among the Zambales, especially among those at-risk.

\section{REFERENCES}

1. Sands, P. (1992). The United Nations framework convention on climate change. Rev. Eur. Comp. \& Int'l Envtl. L., 1, 270.

2. Holdren, J. P. (2006). Meeting the ClimateChange Challenge. [PowerPoint slides] Retrieved fromhttp://www.whrc.org/resources/essays/20052006.html\#sthash.vDkM3KIF.dpu

3. World Commission on Environment and Development (WCED). (1983). Report of the World Commission on Environment and Development - Our Common Future. https://sustainabledevelopment.un.org/milestones/ wced

4. Christianson, G. E. (1999). Greenhouse: The 200year story of global warming. New York: Walker cs.fit.edu/ jpmcgee/classes/CSE5800/

5. World Bank. (2008). International Finance Corporation; Multilateral Investment Guarantee Agency. Development and Climate Change: A Strategic Framework for the World Bank Group Technical Report. World Bank, Washington, DC. (C) World Bank. https://openknowledge.worldbank.org/handle/1098 6/28201 License: CC BY 3.0 IGO."

6. Shanahan, M. (2007). Talking about a revolution: Climate change and the media: An Than, N. T. (2001). Awareness of Vietnamese primary school teachers on environmental education. International Research in Geographical and Environmental Education, 10(4), IIED Briefing. www.iied.org.
7. World Development Report. (2005). A Better Investment Climate for Everyone. Open Knowledge Repository. https://openknowledge.worldbank.org/handle/1098 6/5987?locale-attribute $=\mathrm{fr}$

8. Diviva, P., Pasamba, M., \& Panado. (2013). Disaster preparedness, response and post management system of the province of Zambales.

9. Sutton, J., \& Tierney, K. (2006). Disaster Preparedness: Concepts, Guidance, and Research Natural Hazards Center Institute of Behavioral Science University of Colorado Boulder, CO http://www.colorado.edu/hazards

10. Intergovernmental Panel on Climate Change (IPCC). (2014). Climate Change 2014 Synthesis Report Summary Chapter for Policymakers. IPCC, 2014.

11. Banwell, N., Montoya, J., \& Opeña, M. (2016). Developing the Philippines as a Global Hub for Disaster Risk Reduction - A Health Research Initiative as Presented at the 10th Philippine National Health Research System Week Celebration doi: 10.1371/currents.dis.5cf90566bb7791456dcf6b9ba f6d4873https://www.ncbi.nlm.nih.gov/pmc/article s/PMC5109717/

12. Ayandele, A., \& Jegede, M. O. (2016). Climate Change Education and Knowledge among Nigerian University Graduates. Weather Climate and Society, 8(4):465-473.

13. Agboola, O. S., \& Emmanuel, M. (2016). Awareness of Climate Change and Sustainable Development among Undergraduates from two Selected Universities in Oyo State, Nigeria.URL: http://dx. doi.org/10.5430/wje.v6n3p70

14. Holten Y. V. (2017). The impacts of global climate change in Indonesia: Jakarta as a case study," AM PRO WORLD, 2015, http://iamproworld.com/2017/05/11/the-impactsof-global-climate-change-in-indonesia-jakarta-asa-case-study/.

15. World Bank. (2013). Climate Change: Sector Results Profile. Climate Change. https://www.worldbank.org/en/results/2013/04/13/ climate-change-results-securing\%20finance.

Cite This Article: Esmen M. Cabal et al (2021). Awareness on Climate Change and Adaptation Capability Needs of the Residents of Zambales, Philippines. East African Scholars J Edu Humanit Lit, 4(3), 105-113. 